\title{
A CRISE DO SISTEMA POLÍTICO BRASILEIRO NO SÉCULO XXI A LUZ DAS CONCEPÇÕES DE MONTESQUIEU
}

\author{
THE CRISIS OF THE BRAZILIAN POLITICAL SYSTEM IN THE 21ST CENTURY \\ THE LIGHT OF THE CONCEPTIONS OF MONTESQUIEU
}

\author{
Lorena dos Santos Almeida ${ }^{1}$ \\ https://orcid.org/0000-0003-3917-0149 \\ http://lattes.cnpq.br/0915126293953052
}

Cássia Plácido de Oliveira ${ }^{2}$

https://orcid.org/0000-0003-0098-8082

http://lattes.cnpq.br/6462471326793286

Marcos Vinicius Viscaia Guardia ${ }^{3}$

https://orcid.org/0000-0001-5441-5154

http://lattes.cnpq.br/0236591936989512

\section{Marilene Françuise da Conceição Trajano 4 \\ https://orcid.org/0000-0002-2877-8821 \\ http://lattes.cnpq.br/0622093138595469}

\section{Rafael Giovani Hansseler Saldanha5 \\ https://orcid.org/0000-0002-4665-3870 http://lattes.cnpq.br/9522223296234090}

Recebido em 26 de abril de 2018.

Aprovado em 17 de março de 2020.

RESUMO: O estudo teve como propósito mostrar a relevância das concepções de Montesquieu abordando alguns conceitos de leis, tipologia de poder, liberdade política, corrupção e separação dos poderes a fim de compreender a crise do sistema político

\footnotetext{
1 Graduada em Terapia Ocupacional pela Universidade do Estado do Pará - UEPA (2010). Mestrado Profissional em Planejamento e Políticas Públicas pela Universidade Estadual do Ceará - UECE (2019). Especialização em Docência no Ensino Superior pela Faculdade Ávila (2014). E-mail: lorenaalmeida8@gmail.com

${ }^{2}$ Graduada em Administração pela Faculdade Estácio do Amapá (2013), pós-graduada em Docência do Ensino Superior pelo Instituto de Ensino Superior do Amapá (2014) e Mestre em Planejamento e Políticas Públicas pela Universidade Estadual do Ceará (2019). E-mail: cassiaubj@,hotmail.com

${ }^{3}$ Graduação em Química pela Universidade do Estado do Amapá (2015), pós-graduação lato sensu em Gestão e Docência no Ensino Superior pela Faculdade de teologia e ciências humanas - FATECH (2016), mestrado profissional em Planejamento e Políticas Públicas pela Universidade Estadual do Ceará - UECE (2019). E-mail: marcosguardia92@gmail.com

${ }^{4}$ Graduada em licenciatura e bacharelado em geografia pela Universidade Federal do Amapá (2007). Especialista em Gestão Urbana pela Universidade Federal do Amapá. Mestre em planejamento e políticas públicas pela Universidade Estadual do Ceara (UECE). E-mail: franuise@gmail.com

${ }^{5}$ Discente do Mestrado Profissional em Planejamento de Políticas Públicas (MPPPP) da Universidade Estadual do Ceará (UECE). Licenciado em Letras/Habilitação em Língua Espanhola (UFPA, 2012); Especialista em Produção de Material Didático e Formação de Mediadores de Leitura para a Educação de Jovens e Adultos-EJA (UNIFAP, 2017); Especialista em Docência do Ensino Superior (Faculdade META, 2014). E-mail: rafael.rafaelsaldanha.saldanha@gmail.com
} 
brasileiro. A pesquisa teve como base a seguinte problemática: Qual o possível diagnóstico da crise pela via deterioração das relações entre o poder executivo e legislativo? O objetivo volta-se para verificar o possível diagnóstico da crise pela via deterioração das relações entre o poder executivo e legislativo e os objetivos específicos, identificar as concepções de Montesquieu enquanto crítico político; investigar a crise do sistema político brasileiro no século XXI e verificar a sua relação com a teoria de separação dos três poderes de Montesquieu. Trata-se de uma pesquisa bibliográfica de cunho qualitativo.

Palavras-chave: Crise do Sistema Político Brasileiro. Corrupção. Separação dos Poderes.

\begin{abstract}
The purpose of the study was to show the relevance of Montesquieu's conceptions by addressing some concepts of laws, typology of power, political freedom, corruption and separation of powers in order to understand the crisis of the Brazilian political system. The research was based on the following problematic: What is the possible diagnosis of the crisis through the deterioration of relations between the executive and legislative branches? The objective is to verify the possible diagnosis of the crisis through the deterioration of the relations between the executive and legislative power and the specific objectives, to identify the conceptions of Montesquieu as a political critic; To investigate the crisis of the Brazilian political system in the 21 st century and to verify its relation with the theory of separation of the three powers of Montesquieu. This is a qualitative bibliographical research.
\end{abstract}

Keywords: Crisis of the Brazilian Political System. Corruption. Separation of Powers.

\title{
1 INTRODUÇÃO
}

O cenário político do Brasil, em 2016, foi marcado por uma profunda crise, evidenciada pelo impeachment da presidente, Dilma Roussef, e a enorme desarmonia entre os poderes executivo, legislativo e judiciário, entre outros. Para Avritzer (2016), o Brasil vivencia impasses em sua democracia, configurada por uma crise de crescimento e evolução democrática. O autor aponta que os principais elementos envolvidos nesta crise são: a grande coalisão do presidencialismo; a dificuldade na participação popular na política; a corrupção e seus efeitos; e o novo papel do Poder Judiciário.

$\mathrm{Na}$ ciência política, destaca-se o clássico autor Montesquieu que tratou de inúmeros conceitos e teorias no século XVIII, como a tipologia do poder e a teoria dos três poderes. O objetivo da tripartição dos poderes políticos é para evitar a concentração do poder nas mãos de uma única pessoa, ou seja, quando um poder tenta dominar o outro ou usurpar suas atribuições acaba ocorrendo uma desarmonia entre eles.

Entende-se que isso é fruto das dificuldades que os poderes têm em executar sua função precípua de forma harmoniosa e impessoal, sem a interferência constante dos demais, de modo a comprometer o seu andamento. Isto posto, vê-se os interesses particulares de cada poder se sobrepondo aos interesses coletivos, a não delimitação clara da interferência de um poder sobre o outro e a dificuldade de dar continuidade em ações políticas e públicas em prol do bem comum.

Pode-se citar como exemplo o episódio do afastamento da presidente da República, Dilma Rousself, que resultou uma fragilidade e desequilíbrio da relação deles. Acredita-se que sua análise acerca das formas e organização do governo pode ser observada ainda nos dia de hoje. Nesse contexto, surgiu o interesse em pesquisar a respeito da crise política no Brasil a luz dos conceitos de Montesquieu, buscando responder o seguinte questionamento: Qual o possível 
diagnóstico da crise pela via deterioração das relações entre o poder executivo e legislativo?

Pretende-se com esta pesquisa identificar as concepções de Montesquieu enquanto crítico político; investigar a crise do sistema político brasileiro no século XXI e verificar a sua relação com a teoria dos três poderes de Montesquieu, a fim de verificar o possível diagnóstico da crise pela via deterioração das relações entre o poder executivo e legislativo. Assim, o estudo apresenta relevância acadêmica e social, uma vez que propiciará compreender o processo político em que vivemos, bem como as teorias de Montesquieu, de modo a levar a uma reflexão da sociedade sobre o sistema democrático atual do Brasil.

Trata-se de uma pesquisa bibliográfica de cunho qualitativo acerca da temática por meio de livros e artigos científicos, em que foram pesquisadas as obras de Montesquieu e seus principais comentadores; e ainda os teóricos que tratam das ciências políticas.

\section{A OBRA “DO ESPÍRITO DAS LEIS"}

O Espírito das Leis, foi o mais importante livro de Montesquieu publicado em 1748 e é fruto de um pensamento elaborado na primeira metade do século XVIII, obra de um pensador, único na sua época, que considerava os problemas políticos em si mesmos, sem ideias pré-concebidas sobre o espírito e a natureza. Nesta obra o autor defendeu que toda forma de governo deveria obedecer às leis e não à vontade do monarca e da religião. E também elaborou a divisão da tripartição dos poderes que existe em todos os governos liberais e democráticos.

Conforme, Manuel Amaral (2008),

[...] O método de Montesquieu consistiu em examinar as leis positivas nas suas relações entre si, mostrando que, pela sua própria natureza, determinadas leis tanto implicavam como excluíam outras. Havia, por isso, entre as leis positivas, relações naturais de exclusão e de inclusão, dirigidas não pela arbitrariedade de um homem ou de uma assembleia, mas pela necessidade das coisas.

Para o autor, Montesquieu defendia que o governante teria que ser a pessoa de confiança dos cidadãos e que representaria a vontade da sociedade e não interesses de uma única pessoa. Esse governo deveria está limitado às legislações criadas por outro grupo (legislativo) e julgado pelos tribunais, assim limitaria o poder absolutista dos reis. Também pregava a necessidade de um conjunto de leis que expressassem os valores da sociedade, e que fossem obedecidas inclusive pelos governantes: seria a Constituição de um Estado com a divisão de tarefa bem definida.

Nesse sentido, a função precípua do autor é encontrar modelos de sociedades que provoque a inspiração dos legisladores, grupos sociais que são muitas vezes expostos como instrumentos mecânicos - uma comparação típica do século XVIII - que foram criados e modificados pela criatividade humana de acordo com relações de necessidades, que foram sendo estabelecidas ao longo dos tempos. Montesquieu deixa claro sua preocupação com o entendimento das gerações futuras, e de acordo com o prefácio da obra “o espírito das leis” pode-se observar,

Não escrevo para censurar o que se acha estabelecido em qualquer país. Cada nação encontrará aqui as razões de suas máximas, das quais naturalmente será extraída esta consequência: de que só é dado propor mudanças aos que nasceram com a felicidade de, com um golpe de gênio, compreender toda a constituição de um Estado (MONTESQUIEU, 2000, p. 14). 
Portanto, com o passar dos anos, pôde-se perceber que suas teorias exerceram uma profunda influência no pensamento do sistema político atual, tendo reflexo no sistema político brasileiro. Conforme consta no artigo segundo da constituição: "São Poderes da União, independentes e harmônicos entre si, o Legislativo, o Executivo e o Judiciário” (BRASIL, 1988, p. 292).

\subsection{CONCEITO DE LEIS}

De acordo com Althusser (1968), o conceito de inclusão de lei científica nas ciências humanas foi um necessário legado para compreender a noção de lei em Montesquieu, na qual explica lei como as relações necessárias oriundas da natureza das coisas, para melhor entender e analisar as teorias refletidas em sua obra, como a teoria da tipologia dos governos e a teoria da separação dos poderes. Ele aproximou essa noção de lei às ciências empíricas, afastando da visão ligada a questões divinas.

Montesquieu acredita na possibilidade de existir uniformidades nos comportamentos e formas de organização humana. Segundo Aron (1999) ele traçou três tipos distintos de leis: as leis civis (relacionadas a vida familiar); leis penais e leis constitutivas do regime político. Com isso, a lei está configurada em dois sentidos: um significado seria uma ordem ou indicação do legislador, ou seja, é formal e explícita, sendo chamada de lei-preceito e o outro significado é a compreensão de lei como uma relação de causalidade.

Conforme Albuquerque (2006), Montesquieu sublinhou que as leis das instituições políticas estão explicadas nas relações entre as classes de um povo, suas formas de organizar a economia, o poder, entre outros. Observa-se que a sua preocupação não está nas leis existentes nas relações entre os homens de modo global, mas sim, nas leis positivas. É relevante destacar a abordagem das relações em que elas estão inseridas, como as questões geográficas, climáticas, econômicas, costumes, enfim todas as características de uma nação.

Nesse sentido, Albuquerque (2006) assevera que essas relações entre as leis positivas e as diversas características de um povo é o "Espírito das Leis". Assim, Montesquieu analisa as leis e instituições dos homens a luz de leis da ciência política, confirmando que ambas não são isoladas entre si, porém revelam um processo contínuo de construção que considera todas as especificidades de uma nação. Corroborando com esta mesma ideia, Aron (1999) afirma que sua pretensão é esclarecer a diversidade das leis positivas de forma causal, e também exprimir pontos válidos e universais para embasar os juízos de valor das instituições.

Um aspecto abordado por Montesquieu é a relação das leis com a hierarquia dos seres, tendo como ponto de partida a natureza inorgânica até chegar ao homem. Assim, Aron (1999, p. 45) descreve a análise de Montesquieu:

Quando se trata da matéria, essas leis são pura e simplesmente leis causais; essas são as leis necessárias, que não podem ser violadas. Quando chegamos à vida, as leis são também leis causais, embora de natureza mais complexa. Finalmente, quando chegamos ao homem, essas leis, nos diz Montesquieu, impondo-se a um ser inteligente, podem ser violadas, porque a liberdade acompanha a inteligência. As leis relativas à conduta humana não são mais do tipo de causalidade necessária.

Ainda segundo Aron (1999) observa-se que a possibilidade de violação das leis racionais pelos homens, não refleti em uma inferioridade do mundo inteligente ao mundo físico, o que

PRACS: Revista Eletrônica de Humanidades do Curso de Ciências Sociais da UNIFAP https://periodicos.unifap.br/index.php/pracs ISSN 1984-4352 Macapá, v. 13, n. 1, p. 103-114, jan./abr. 2020 
existe na verdade é uma expressão da liberdade humana. Uma das interpretações sugeridas pelo autor é a reflexão de que o conjunto de relações existentes no meio deve orientar o elaborador das leis, nesse sentido Montesquieu desvelou, ainda, ser possível relacionar as leis ao fim de uma atividade humana.

\subsection{TIPOLOGIA DE PODER}

No século XVIII na França, no período do Absolutismo, Montesquieu era visto como autor liberal, o seu grande enfoque foi à garantia da liberdade individual, a qual lhe deu subsidio para questionar a lei divina da época. Em sua obra "O Espírito das Leis" analisou o sistema político, descrevendo a importância do estudo das leis na formulação da tipologia de poder.

Neste sentido, Montesquieu definiu a questão da natureza do regime político da época, afirmando como estrutura política que possibilita compreender de que forma cada governo legisla e quantas pessoas governam. Para Albuquerque (2006, p. 04)

[...] Os primeiros pensadores políticos que precedem Montesquieu e Rousseau, que o sucede, são teóricos do Contrato Social (ou do Pacto), estão fundamentalmente preocupados com a natureza do poder político, e tendem a reduzir a questão da estabilidade do poder à sua natureza $[\ldots]$.

A primeira natureza foi o Despotismo comumente chamado por Montesquieu como um Estado Absolutista, um governante legisla da forma que achar viável, sem interferência de outras legislações, sendo um déspota, ou comumente um ditador. Conforme Murachco (2000, p. 28) "resulta da natureza do poder despótico que o único homem que o exerce faça-o da mesma forma ser exercido por um só".

Nesta forma de governar, existe uma comparação com as ideias de Hobbes, quando o mesmo analisou a saída do "Estado de Natureza" para o "Estado de Sociedade", propondo apenas que uma única pessoa governasse do jeito que bem entendesse. Seu princípio estava vinculado ao medo afirmando que as pessoas viviam em um estado de insegurança por não ter nenhum tipo de garantia jurídica. Montesquieu afirmou também que o déspota possuía medo, uma vez que podia sofrer uma revolução da população ou um golpe de Estado.

A República, outra forma de natureza vista por Montesquieu se relacionava com a ideia de Aristocracia, na qual todos são cidadãos, tem direitos de criar leis, mas na prática alguns exercem o direito em nome dos demais. A República democrática seria que todos governassem, fazendo uma relação às ideias de Rousseau em o contrato social, na qual afirmava que em uma democracia direta todos criam as leis e governam. O período descrito por Montesquieu foi marcado por concepções de formação de Estado, o que eventualmente trouxe questionamentos quanto à forma de governar. A virtude sendo um princípio vinculado a república é semelhante à ideia de Rousseau, quando o mesmo em suas análises descreveu que em uma sociedade todos criam as leis em prol de um bem comum, ou seja, visando o coletivo.

Murachco (2000, p. 23-24) afirma que:

[...] na aristocracia, o poder soberano está nas mãos de certo número de pessoas. São elas que elaboram as leis e que mandam executá-las; e o resto do povo está para elas, no máximo, como súditos está para o monarca numa monarquia[...]. 
No Estado Francês o sistema vigente era o Absolutismo, onde o monarca gerenciava o poder já estabelecido por intermédio da igreja, não tendo liberdade de formular suas próprias leis, surge nesse momento à forma de governo da monarquia, onde as leis determinadas ao monarca já estava preestabelecidas na qual os indivíduos tinham apenas que seguir o que determinava. A Monarquia era vinculado ao princípio da honra vista como algo negativo, como egoísta, ou seja, o indivíduo buscava ser honrado frente à sociedade, essa honra passa ser compreendida como uma espécie de classificação social.

Segundo Hobsbawm (1996, p. 87) [...] "A monarquia absoluta, conquanto inteiramente aristocrática e até mesmo feudal no seu ethos, tinha destituído reduzido ao mínimo suas velhas instituições representativas "estados" e parlements" [...]. Montesquieu acreditava, por ser algo egoísta cada legislador vai olhar para si no que se refere aos seus interesses, a partir dessa vertente surge a ideia de equilíbrio social, onde cada poder deveria ter seu controle para não haver um desequilíbrio entre eles, surgindo à ideia da separação de poderes.

A separação de poderes foi a principal contribuição de Montesquieu ao regime político da monarquia, para entender a atualidade e o equilíbrio dos poderes. A honra de fato era privada, exercendo a Monarquia um poder que a todos alcança, mas devendo respeitar a lei, que é igual para todos; ou seja, o rei governa, mas está limitado pela lei. As três formas de poder da época juntamente com os princípios fortaleceu sua concepção, permitindo compreender na atualidade o equilíbrio de poder que temos hoje no Brasil: o Executivo, Legislativo e o Judiciário.

\subsubsection{A Liberdade política sob a ótica de Montesquieu}

Conforme Montesquieu (2002, p. 164) o homem é livre quando faz tudo aquilo que é permitido pela Lei. Caso ele faça o que elas proíbem não terá mais liberdade já que o outro também teria esse poder. $\mathrm{O}$ autor enfatiza que faz-se necessário que tenhamos uma sociedade política organizada, em que um poder deve limitar o outro, para que possa efetivar a liberdade.

Cada poder exerce uma finalidade para o qual foi criado, não existe liberdade se os três poderes estiverem concentrados nas mãos de uma pessoa, pois as leis seriam criadas de forma benéfica para si próprio. Tudo estaria perdido se uma pessoa ou grupo exercesse os três poderes: o de fazer as leis, o de executar as resoluções públicas e o de julgar os crimes ou as querelas entre os particulares. (MONTESQUIEU, 2002, p. 166).

Montesquieu (2002, p. 164) afirma que "a liberdade política só se encontra nos governos moderados", para se ter esse tipo de governo precisa-se combinar os poderes, regulá-los e temperá-los, a fim de que não haja acumulação numa mesma entidade. O autor afirma que a liberdade política ocorre nas monarquias quando tem-se distribuição e divisão de poderes.

Nesse sentido, ele descreve a Inglaterra como exemplo de um estado que visa diretamente a liberdade política, enquanto as demais monarquias a possuem unicamente de forma implícita. Porém, a liberdade não está diretamente relacionada a forma de governo, o povo é livre porque o governo é estabelecido pelas leis. Isso pode acontecer não só na república, mas também na monarquia, desde que exista uma ordem constitucional baseada na lei.

Althusser (1968) não concorda com Montesquieu quando diz que a liberdade política acontece quando há uma única partilha de poder. Montesquieu admite que "a monarquia possa subsidiar e mesmo conservar a sua moderação, se o rei detiver, além do executivo, o poder legislativo". E que para ter uma liberdade absoluta, necessita-se colocar como padrão de confronto: a separação total dos três poderes. 


\subsubsection{A Corrupção do governo}

Ao se falar em corrupção, pensamos logo em política, contudo esse ato de corromper alguém ou algo com a finalidade de obter vantagens de forma ilícita não está presente só na política, portanto, o que acontece nos governos são reflexos de nossas atitudes. Com isso, Albuquerque (2006, p. 161) afirma que para Montesquieu a corrupção dos governantes quase sempre começa com a corrupção dos seus princípios.

Nesse sentido, caso o princípio do governante esteja corrompido circulará a corrupção no seu governo. De acordo com Aron (1999, p.11) "a natureza do governo é o que faz com que ele seja o que é”. No governo despótico tem-se uma natureza corrupta, está ligada a uma só pessoa e faz referência a um regime totalitário, onde quem detém o poder governa sem leis e sem regras. No governo republicano o povo detém o poder soberano. No governo monárquico também está ligado a um só governante mas mediante leis fixas e estabelecidas.

A questão da corrupção tem sido bastante debatida na atualidade. Vive-se um período em que muitos escândalos públicos tem comprometido a máquina pública, os políticos não estão preocupados com os interesses da sociedade, mas em se manter no poder, a qualquer custo. Os poderes que deveriam funcionar de forma harmônica (mecanismos de freios e contrapesos ou check and balances - como nos federalistas) passam a atuar um contra o outro configurando uma crise institucional.

Montesquieu atribuía a estabilidade dos sistemas políticos a essa forma equilibrada de funcionamento dos poderes. A forma como os poderes estão dispostos favorece o florescimento da corrupção. Portanto, "todo homem que tem poder é levado a abusar dele." (MONTESQUIEU, 2002, p. 198).

\subsection{TEORIA DE SEPARAÇÃO DOS PODERES}

Albuquerque (2006, p. 119) afirma que Montesquieu "estabelecia como condição para o Estado de direito, a separação dos poderes executivo, legislativo e judiciário e a independência entre eles". O autor defende a ideia de assegurar que um poder contrarie o outro poder, com isso, evitaria um problema político do governo, que é o do abuso de poder.

Contudo, Eisenmann (1933, p. 133-160) faz uma crítica a essa teoria dizendo que ela é nada além de um mito e que o problema de Montesquieu é mais político do que jurídico. Para Montesquieu cada órgão exerce uma atribuição diferente, mas ele não deixa claro a relação entre os órgãos. O Executivo interfere no Legislativo, este exerce controle sobre o Executivo e o Legislativo assume tarefas, a princípio, próprias do Judiciário. Portanto, a teoria da separação dos poderes esbarra no reconhecimento de que os órgãos não estão funcionando separados, mas o que há, na verdade, é uma combinação dos poderes.

O autor enfatiza, que, para Montesquieu (2002, p. 169), o Judiciário é um poder praticamente "nulo", na medida em que a função dos juízes consiste apenas em ler e dizer a lei, sem regular o alcance nem o rigor da mesma. E que a sua principal preocupação é sobre as relações de forças e o equilíbrio dos poderes. A partir dessa análise, Althusser (1968) ressalta que, para Montesquieu, o Legislativo não pode usurpar poderes do Executivo, mas que o inverso seria possível e exclui a possibilidade do Executivo acumular, também, o poder Judiciário. 


\section{CRISE DO SISTEMA POLÍTICO BRASILEIRO NO SÉCULO XXI}

\subsection{DIAGNÓSTICO DA CRISE PELA VIA DETERIORAÇÃO DAS RELAÇÕES EN- TRE O PODER EXECUTIVO E LEGISLATIVO}

O presidencialismo de coalizão é um sistema através do qual se dá a relação entre o executivo e o legislativo. Esse arranjo político-constitucional, que ocorre no Brasil, têm-se um sistema majorativo de eleições presidencial e proporcional fragmentado de eleição pelo congresso. O partido do presidente não consegue fazer vinte por cento $(20 \%)$ das cadeiras do congresso nacional, então institui amplas coalizões para estabelecer a possibilidade de governabilidade do país.

Nesse sentido, Frota (2016, p. 167) afirma que para Avritzer, o presidencialismo de coalizão é um dos impasses do sistema político brasileiro no qual "o presidente do Brasil se elege com uma quantidade muito maior de votos do que seu partido recebe nas eleições para o Congresso Nacional, criando a necessidade de alianças políticas".

Para o autor isso resulta em dois procedimentos: um, seria, quando o presidente não consegue obter a maioria nas casas legislativas; e o outro, quando se enseja como alternativa de coalizões que despolitizam uma agenda progressista causando, portanto, o distanciamento do partido da sua base de sustentação e uma crise de legitimidade. Em virtude disso, faz-se necessário melhorar ou desfazer esse sistema de coligação proporcional.

O autor enfatiza que, para Weber, a ética de responsabilidade é a única ética possível na política contemporânea, que sugere não fazer coligações proporcionais dessa amplitude com agentes políticos que agem ao contrário de como deveriam. Percebe-se que os acordos entre os partidos políticos tem como finalidade, geralmente, a ocupação de cargos em um governo. De acordo com Abranches (1988, p. 13) "Esse é, naturalmente, um processo de negociação e conflito, no qual os partidos na coalizão se enfrentam em manobras calculadas para obter cargos e influência decisória". Como o governo necessita de uma base de sustentação no Legislativo, entende-se a importância dos arranjos de coalizão na atual crise brasileira.

Portanto, Batista (2016) afirma que se o governo não consegue ter essa base de apoio nos partidos, sua capacidade de governar fica prejudicada, fazendo com que as leis de interesse do governo não sejam aprovadas e consequentemente a execução de políticas públicas fiquem prejudicadas. Com isso, entende-se que esse tipo de arranjo funcionaria se os poderes mantivessem uma relação de diálogos constantes em prol de uma agenda de governo que beneficiasse a população.

\section{RELAÇÃO ENTRE A CRISE DO SISTEMA POLÍTICO BRASILEIRO NO SÉCULO XXI E A SEPARAÇÃO DOS PODERES EM MONTESQUIEU}

O sistema político brasileiro segue, rigorosamente, o modelo proposto pelos federalistas elaboradores da Constituição (1787) dos Estados Unidos - que inspirou com seu texto, inclusive, as constituições adotadas pela maioria dos países latino-americanos ao longo do século XIX - mais que a teoria dos três poderes, esplanada por Montesquieu. É visto, ainda que, o "Espirito das Leis", é base fundamental para compreender, e mesmo comparar com a organização, o funcionamento do sistema atual do Brasil.

O que distancia Montesquieu dos federalistas é que, ele, considerava como poder real 
somente o Executivo e o Legislativo, atribuindo ao Judiciário um papel secundário de intervir quando os dois primeiros falhassem, o judiciário era mais um árbitro, um técnico a analisar e reparar erros cometidos na condução do poder. Já os federalistas apostam no mecanismo dos "freios e contrapesos" para gerar certo equilíbrio no poder das três divisões propostas, quais sejam, o executivo, legislativo e judiciário, sem entrar na discriminação que faz Montesquieu quando atribui ao judiciário papel secundário, menos importante.

Os federalistas afirmavam que, no sistema institucional, a vida pública seria mais oxigenada quando possibilitasse uma intensa deliberação de todos os poderes sobre o mesmo tema, aperfeiçoando cada vez mais as decisões para a vida em sociedade, acreditando-se que quanto mais se debate, mais acumula e delibera entre todos os poderes. Quanto ao sistema político idealizado por Montesquieu, caberia ao legislativo, com suas câmaras alta (nobreza) e baixa, debaterem para sanção do executivo. Caso, quando da aplicação, ocorresse a detectação de um erro grave, então assim entraria o judiciário para apontar e sanear o problema.

A crise institucional no Brasil extrapola os limites teóricos, problematizados pelos federalistas e Montesquieu. Trata-se de uma crise ética, motivada pela corrupção estrutural da política brasileira, e que envolve os membros dos três poderes da República.

Simon (2010, p. 33) aponta dois fatores que:

Podem contribuir para a compreensão da crise ética por que passa o Congresso Nacional, por exemplo. O primeiro é a persistência de uma regra eleitoral que, para bem funcionar, exige o recurso a práticas não consideradas legítimas pela opinião pública, vale dizer, pelo eleitorado. O segundo é o positivo aumento da transparência possibilitado pela vigência da Constituição de 1988.

Pode-se citar como exemplo a ocasião que ocorreu, em 2017, quando o chefe do Executivo, Michel Temer, foi envolvido em denúncias, de pelo menos três crimes: obstrução da justiça; corrupção passiva e organização criminosa. E que competia ao poder Legislativo a autorização do julgamento do mesmo.

Para que o processo fosse instaurado seriam necessários 324 votos da Câmara dos deputados, no entanto, não seria certo que o placar de votação, no interior do legislativo, alcançasse essa quantidade mínima de votos, pelo simples fato do presidente ser integrante do partido do movimento democrático brasileiro (PMDB), a maior força da casa de leis, e ainda contar, como aliados, os deputados do partido da social democracia brasileira (PSDB), o que poderia conduzir ao arquivamento da denúncia realizada pela Procuradoria Federal da República.

Não importava que o presidente do Brasil não fosse um homem virtuoso, tão pouco o são os legisladores, vários são os fatos e momentos históricos que comprovaram a inexistência dessa variável, na maioria absoluta dos representantes políticos nacionais. Para Montesquieu, o "Abuso de Poder" só será combatido com um poder que possa refrear o poder. A Ciência Política é uma base teórica criada a partir dessa defesa do autor clássico, de que um poder que julga deve ser independente do poder que legisla e executa.

Ocorre que o sistema político brasileiro é estruturado por mecanismos de corrupção, o que leva ao topo da representação política membros da aristocracia do campo, da indústria nacional e do alto escalação do serviço público. De acordo com Simon (2010, p. 354) a corrupção:

Campeia em todos os escalões dos órgãos públicos, infelizmente agora em todos os níveis. A corrupção, nesta minha escada, está entre os degraus intermediários, porque é um misto de 
causa e consequência. Ao mesmo tempo em que ela é a responsável pelas tantas mazelas dos degraus de baixo, é resultado do que ocorre no degrau superior, o da impunidade.

Avançam-se os séculos e estão lá sempre os mesmos membros das famílias tradicionais e abastadas do país, os que sempre comandaram. Aqui está o ponto alto da contradição da política brasileira, a razão do colapso do poder da República. Não existe independência ou coexistência respeitável entre os poderes. O que existe é uma promiscuidade entre os três. O executivo indica os membros do Supremo Tribunal Federal para blindá-los em votações decisivas dos casos mais possíveis e imagináveis, inclusive perdas de poder. Os deputados e senadores são "financiados" para aprovarem os interesses do Executivo e este, por sua vez, relaxa e facilita regalias de toda ordem.

O último governo do PT foi abreviado a partir de um golpe de Estado muito bem conduzido pelas elites políticas e econômicas, que estavam insatisfeitas com as incessantes vitórias eleitorais do partido junto às urnas. Nessa erupção de escândalos descortina-se uma grande farsa para afastar a presidente Dilma Rousseff, a qual dava total permissão para prosseguirem as operações da justiça e da polícia federal na "caçada" ao crime organizado que arrastava construtoras, lobbystas, políticos, cônjuges e todo o resto, a classe média que aceitou ser manipulada assiste atônita o resultado da manobra.

De outro lado, percebe-se, como reação a este fato, o crescimento imbatível do fenômeno "Lula 2018", colocando o ex-presidente como o único nome com potencial de vitória nas eleições próximas. Possuidor de carisma popular nato, incontrolável e que tira o sono da elite clássica nacional, esta que terá que concluir que toda a movimentação do impeachment foi mera esquizofrenia coletiva, Luiz Inácio Lula da Silva não é de tão puro e tem sua parcela de responsabilidade neste colapso.

Quando governou o país, Lula e seu Partido dos Trabalhadores (PT) optaram por adesão imediata à política de conciliação de classes. Aqui cabe um recorte: não trata-se nem mais de garantir o respeito a convivência independente dos poderes, proposta pelos clássicos da teoria política, mas sim da divisão bem definida de projeto político, diferenciação de concepção de modo de governar, de poder e de sociedade. O governo do PT jamais poderia buscar se conciliar com as classes dominantes representadas por partidos como o PMDB, por exemplo, que sempre detestaram aquilo que o PT defendia.

Em nome da possibilidade de atingir a governabilidade, utilizando o mecanismo do presidencialismo de coalização de que trata Leonardo Avritzer (2016), Lula abraçou como aliados da primeira hora aqueles que, ironicamente, o trairia no segundo mandato de sua sucessora. Resta especular, caso se confirmasse a possibilidade de concorrer e vencer em 2018, como se comportaria o PT num novo governo. Conciliaria, novamente, com as classes políticas tradicionais golpistas, tendo a governabilidade como justificativa, ou teria aprendido a lição e, desta vez, buscaria força nos movimentos sociais e mobilização da sociedade civil para defender seu governo de qualquer ameaça de manobra ou golpe institucional.

\section{CONCLUSÃo}

Tendo em vista os aspectos observados, o estudo procurou explorar e expor as concepções de Montesquieu enquanto crítico político que, com suas ideias, exerceu uma intensa influência no pensamento do sistema político atual, tendo reflexo no sistema político brasileiro. 
Essas influências do autor francês foram tão significativas que, mesmo escrevendo suas obras no século XVIII, houve tema como a separação dos poderes que foi recepcionado pela constituição federal em seu artigo segundo, que possui o seguinte texto "São Poderes da União, independentes e harmônicos entre si, o Legislativo, o Executivo e o Judiciário".

Apesar do conteúdo deste artigo citar que a tripartição dos poderes são "independentes e harmônicos entre si...” mas na prática percebe-se que não é bem assim, pois para os poderes legislativo e executivo dar cumprimento às suas funções típicas há uma dependência de outros poderes, e vimos que estão bem interligados e dependente.

No cenário político percebemos que o chefe do poder executivo federal (presidente da república) não consegue implementar sua agenda de governo de forma efetiva, pois precisa de aprovações importantes no congresso nacional. Logo se observa que para a efetivação das funções típicas do poder executivo, o partido de quem estar no poder precisa de maioria dos votos de deputados e senadores para ajudar nas aprovações das leis no congresso nacional. Como isso não ocorre de fato, a necessidade de o presidente da república "negociar" com os parlamentares para as aprovações e dar continuidade a sua agenda de governo.

Nesse sentido, vemos que o poder executivo acaba por ser o grande poder da República que possui uma maciça influência nos demais poderes quando, por exemplo, é concedido a ele toda a indicação da composição da Suprema Corte Brasileira, corte essa que, através dela é formada a presidência do tribunal superior eleitoral, tribunais do mais alto escalão que futuramente poderá julgar um presidente da república. Outro ato importante que, atualmente presenciamos, é a edição de medidas provisórias com força de lei, isto somente deveria ocorrer em casos excepcionais, mas é uma arma usada pelo presidente corriqueiramente, em tese, temos o poder executivo exercendo a função precípua do poder legislativo.

Além disso, quando o legislativo atua na função legiferante, criando leis, o poder executivo tem o poder de veto, ou seja, o presidente pode vetar parcial ou totalmente os projetos de leis que saem do Congresso Nacional. A relação entre o chefe do poder executivo e os parlamentares do Congresso Nacional pode ser vista como o problema institucional mais importante da atual conjuntura política brasileira. Além desses impasses institucionais que se presencia, há também a corrupção que é frequente no cenário político brasileiro, atrapalhando as relações de poder e consequentemente substituindo os interesses.

Assim, os sujeitos que a praticam estão substituindo os interesses públicos pelos benefícios próprios. Têm-se como exemplo disso, no Brasil, a operação lava jato que desencadeou a maior investigação de corrupção e lavagem de dinheiro que o país já teve. Estima-se que o volume de recursos desviados dos cofres da Petrobras, esteja na casa de bilhões de reais. Em virtude disso, tentou-se avaliar as ideias de autores renomados contextualizando com o cenário da política para tentar compreender a crise do sistema político brasileiro no século XXI e verificar os possíveis diagnósticos da crise política que afeta o Estado democrático de direito brasileiro, pela via do desgaste que há nas relações entre os poderes executivo e legislativo.

Levando-se em consideração esses aspectos, mudança precisa ser feita para amenizar a corrupção com os problemas institucionais. As mais significativas são: na forma que se dar a composição da mais alta corte do país, o Supremo Tribunal Federal (STF), por exemplo, pela maior participação dos outros poderes da república nesta corte, deixar de ser mera indicação do chefe do executivo; limitar as criações de Medidas Provisórias pelo presidente da república, impondo regras para seu uso, deixando mais limitado à função atípica do executivo; e por fim, criar formas de amenizar o presidencialismo de coalizão no país. Outra medida fundamental 
é a punição mais severa para políticos e partidos políticos corruptos que se envolvam com a corrupção.

Acredita-se que a análise das atuais relações políticas e o debate político da sociedade possam favorecer a construção de novas formas de se pensar o sistema político brasileiro, sendo importante a existência de definições das funções dos poderes e controles de um poder sobre o outro para garantir uma relação de fato independente e harmônica em prol do poder soberano do povo.

\section{REFERÊNCIAS}

ABRANCHES, Sérgio Henrique Hudson de. Presidencialismo de Coalizão: o Dilema Institucional Brasileiro. Revista de Ciências Sociais. Rio de Janeiro, v. 31, n. 1, p. 5 - 34, 1988 ALBUQUERQUE, J. A. Guilhon. Montesquieu: sociedade e poder. In: WEFFORT, Francisco C. (org.). Os Clássicos da Política. 14.ed. São Paulo: Ática, 2006. p. 111 a 185.

ALTHUSSER, Louis. Montesquieu. A política e a história. Madrid: Editorial Ciência Nova, 1968.

AMARAL, Manuel. Montesquieu e o pensamento político. Portal da História. 2008. Disponível em: <http://www.arqnet.pt/portal/teoria/montesquieu.html>. Acesso em: 16 de Jul. 2017.

ARON, Raymond. As etapas do pensamento sociológico. Tradução Sergio Bath. $5^{a}$ ed. São Paulo: Martins Fontes, 1999.

AVRITZER, Leonardo. Impasses da democracia no Brasil. Rio de Janeiro: Civilização Brasileira, 2016.

BATISTA, Alexandre Lins. Presidencialismo de Coalizão e a atual crise Brasileira. Politize. Florianópolis, 2016. Disponível em: < http://www.politize.com.br/presidencialismo-de-coalizao-e-atual-crise-brasileira/>. Acesso em: 31 Jul 2017.

BRASIL. Presidência da República. Constituição da República Federativa do Brasil, promulgada em 05 de outubro de 1988. Disponível em: <http://www.planalto.gov.br/ccivil_03/Constituicao/Constituicao.htm>. Acesso em: 10 jul 2017.

EISENMANN, C. L'Esprit des Lois et la séparation des pouvoirs. In: MALBERG, R. Mélanges. Paris: Sirey, 1933, p. 133-160.

FROTA, Francisco Horácio da Silva. Resenha. In: AVRITZER, Leonardo. Impasses da Democracia no Brasil, 27, 2016, Rio de Janeiro. O público e o privado. Rio de Janeiro: Civilização Brasileira, 2016, p. 167-170.

HOBSBAWM, E. J. A era das revoluções. 9.ed. São Paulo: Paz e Terra, 1996.

MONTESQUIEU, Charles de Secondat, Baron de. O Espírito das leis. Tradução Jean Melville. São Paulo: Martin Claret, 2002.

, Charles de Secondat, Baron de. O Espírito das leis. Apresentação Pedro Jaime Ribeiro, Tradução Cristina Murachco. São Paulo: Ed. Martins Fontes, 2000.

SIMON, Pedro. A impunidade veste colarinho branco. Brasília: Senado Federal, 2010, p. 386. Disponível em: <https://www2.senado.leg.br/bdsf/bitstream/handle/id/193076/livro048.pdf?sequence $=>$. Acesso em: 14 fev 2020 . 